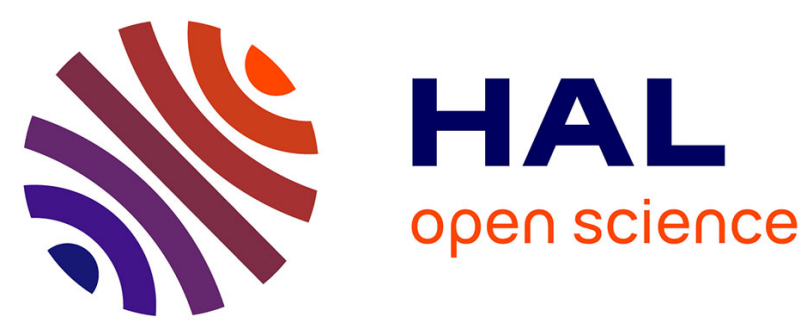

\title{
INTERGRANULAR SULFUR SEGREGATION AND GRAIN BOUNDARY PLANE IN A NICKEL BICRYSTAL
}

\author{
W. Swiatnicki, S. Lartigue, M. Biscondi, D. Bouchet
}

\section{- To cite this version:}

W. Swiatnicki, S. Lartigue, M. Biscondi, D. Bouchet. INTERGRANULAR SULFUR SEGREGATION AND GRAIN BOUNDARY PLANE IN A NICKEL BICRYSTAL. Journal de Physique Colloques, 1990, 51 (C1), pp.C1-341-C1-346. 10.1051/jphyscol:1990154 . jpa-00230315

HAL Id: jpa-00230315 https://hal.science/jpa-00230315

Submitted on 1 Jan 1990

HAL is a multi-disciplinary open access archive for the deposit and dissemination of scientific research documents, whether they are published or not. The documents may come from teaching and research institutions in France or abroad, or from public or private research centers.
L'archive ouverte pluridisciplinaire HAL, est destinée au dépôt et à la diffusion de documents scientifiques de niveau recherche, publiés ou non, émanant des établissements d'enseignement et de recherche français ou étrangers, des laboratoires publics ou privés. 


\title{
INTERGRANULAR SULFUR SEGREGATION AND GRAIN BOUNDARY PLANE IN A NICKEL BICRYSTAL
}

\author{
W. SWIATNICKI, S. LARTIGUE, M. BISCONDI* and D. BOUCHET \\ Laboratoire de Métallurgie structurale, ISMA, Bat. 413, Université \\ Paris XI, F-91405 Orsay, France \\ "Ecole Nationale Superieure des Mines, 158 cours Fauriel, F-42025 saint \\ Etienne, France
}

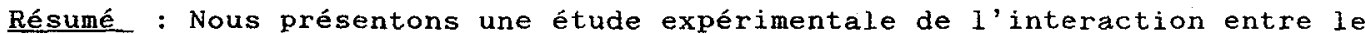
niveau de ségrégation intergranulaire du soufre et la structure d'un bicrystal $\Sigma 11$ de nickel. De plus, l'influence d'un traitement de désulfuration effectué sur lames minces, sur les paramètres cristallographiques du joint de grains et les dislocations intergranulaires est analysée.
\end{abstract}

Abstract : We report an experimental study of the interaction between sulfur intergranular segregation level and grain boundary structure of a nickel bicrystal $\Sigma 11$. Furthermore, the influence of desulfidation treatment, performed on the thin foils, on the grain boundary cristallographic parameters and intergranular dislocations is analysed.

\section{INTRODUCTION}

Although widely investigated, the relationship between grain boundary structure, energy and intergranular segregation remains imprecise and controversed [1]. Recently, some theoretical studies tended to privilege the role of the grain boundary plane in the propensity for a GB to accept segregated species. [2, 3, 4]. According to statistical experimental data obtained on nickel polycrystals, we had previously suggested that the interplanar spacing $\left.\left(-d_{h k l} / a\right)-\right)(a=$ lattice parameter $)$ of the GB plane, could be a better criterion for intergranular sulfur segregation than the misorientation [5, 6]; interplanar spacing being proportionnal to the planar atomic density, the higher (d/a) the smaller the content of segregated impurities in the GB.

Furthermore, computer calculations of segregation energy, made on $\Sigma 11$ GB, show that this energy is higher for the bicrystal $\Sigma 11(332)-d / a=0.114 i-$ than for $\Sigma 11(311)-\mathrm{d} / \mathrm{a}=0.3015-[7]$.

To go further in the investigation of the phenomenon, we have undertaken the study of well-defined low $\Sigma$ GBs, namely two $\Sigma 11$ nickel bicrystals with different orientation planes : (311) and (332). This paper reports the TEM results of the evolution of geometrical $\mathrm{GB}$ parameters related to the variations of intergranular sulfur segregation in the bicrystal, in the case of the $\Sigma 11$ (311) GB. Furthermore, these TEM results are compared to those obtained on the same foils submitted to a desulfidation thermal treatment which allows to remote the sulfur from the GBs* [6].

* B. AUFRAY from Laboratoire de Métallurgie, Marseille, is acknowledged for having performed the desulfidation treatments. 
MATERIAL AND TECHNIQUES

The tilt bicrystal $\Sigma 11$ ( 311 ) $\left(50^{\circ} 48\right.$ around $\langle 110\rangle$ ) has been elaborated by unidirectional solidification, followed by slow cooling; the misorientation has been controlled by $x$ ray diffraction and ECP pattern. The chemical composition is given in table $I$.

TABLE I : Bulk composition of the bicrystal (weight ppm).

\begin{tabular}{|c|c|c|c|c|c|c|c|c|c|c|c|c|}
\hline & 0 & $\mathbf{S}$ & Al & $\mathrm{Fe}$ & $\mathrm{Ca}$ & As & $\mathrm{Sb}$ & V & $\mathrm{Cu}$ & $\mathrm{Pb}$ & Si & P \\
\hline PART I & $<20$ & $<10$ & 190 & 235 & 15 & 4 & $<1$ & $<1$ & 11 & 2 & 50 & $<20$ \\
\hline 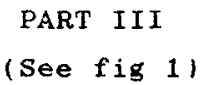 & $<20$ & $<10$ & 130 & 230 & $<10$ & 5 & $<1$ & $<1$ & 11 & $<1$ & 20 & $<20$ \\
\hline
\end{tabular}

The sulfur content is less $10 \mathrm{ppm}$ which is sufficient to promote strong intergranular sulfur segregation.

The bicrystal has been cut in four pieces (Fig. 1 ) : parts I (close to the nucleus) and III are used for chemical etching and TEM structure study; parts II and IV are devoted to Auger spectroscopy. Chemical etchings, performed during several minutes in a mixture of $50 \%$ vol $\mathrm{HNO}_{3}-50 \%$ vol. HF, allows to reveal intergranular sulfur segregation observed by optic metallography. The structure of the different zones of the GB is analysed in a $200 \mathrm{kV} T E M$ : the misorientation is determined by Kikuchi lines analysis ; accuracy on the deviation $\Delta \theta$ from the coincidence is better than $0.2^{\circ}$. The indices of the GB plane are chosen to be the lowest ones within $2^{\circ}$ of the experimental data. In case of asymmetrical $G B$, a mean value (d/a). is taken into account [2]. The Burgers vector of intergranular dislocations are studied by the Marukawa method [8].

\section{INTERGRANULAR SEGREGATION}

AES analysis is not feasible on the part II which is not brittle even after hydrogen charging, implying no sulfur segregation. On the opposite, the part IV is highly brittle. The corresponding AES spectrum (Fig 2) displays only two intergranular segregated species: phosphorus and sulfur. A quantitative estimation of the intergranular concentration leads to the following values of $\sim 80 \%$ at sulfur. These results emphasize the presence of an important sulfur concentration gradient in the bicrystal.

Chemical etchings reveal two kinds of etching groove gradients (fig 3 ): the first one is parallel to the growth direction of the bicrystal (in agreement with the composition gradient revealed by AESl, i.e. the groove is deeper in part III than in part I ; the second one is perpendicular to the growth direction, is clearly visible on figure $3 b$ in part I : the groove becomes more important with the curvature variation of the GB far from the nucleus. Furthermore, subgrains boundaries occur in the bicrystal and induce slight changes in the curvature of the GB and in the etching.

Thus, from now on, it is clear that segregation depends on GB plane and/or deviation from coincidence.

\section{GRAIN BOUNDARY PLANE AND DEVIATION FROM COINCIDENCE AS A FUNCTION OF SEGREGATION}

Thin foils have been extracted from four zones of the GB, presenting various sulfur contents : corresponding descriptions can be roughly summarized as follows (see fig.1):

IA = symmetrical GB with no segregation

IB = asymmetrical GB with no or very poor segregation

IIIA and IIIB = asymmetrical GBs with strong segregations. 


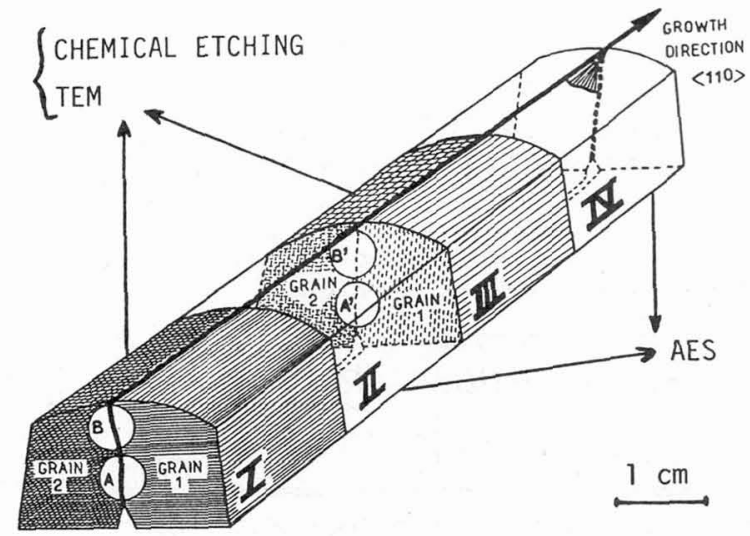

Fig 1 : Shematical representation of the $\Sigma 11$ bicrystal. Thin foils are extracted from "carots" located in $A, B, A^{\prime} B$ ' of parts I and III.

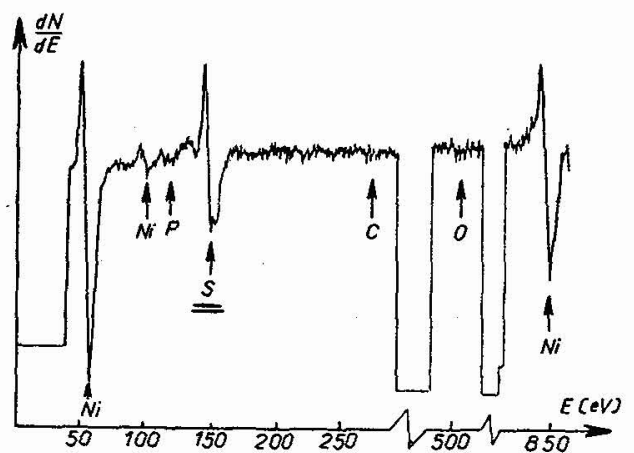

Fig 2 : Auger spectrum of the GB in part IV of the bicrystal. Note the high level of sulfur.

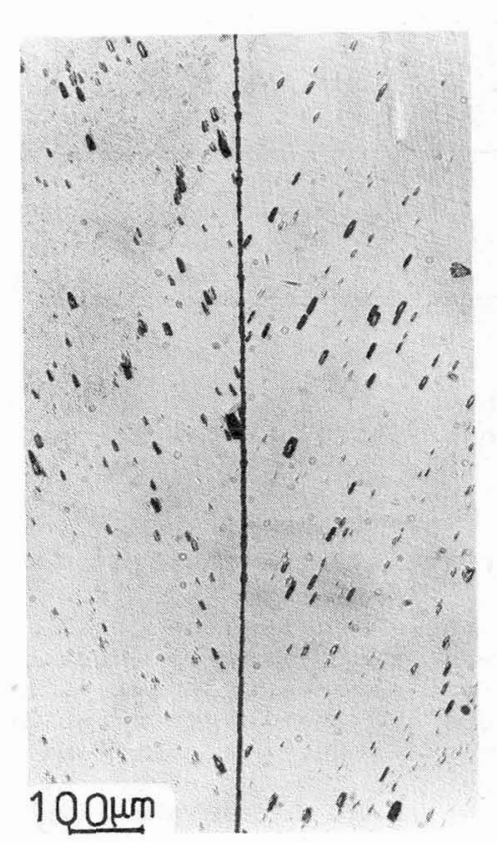

a

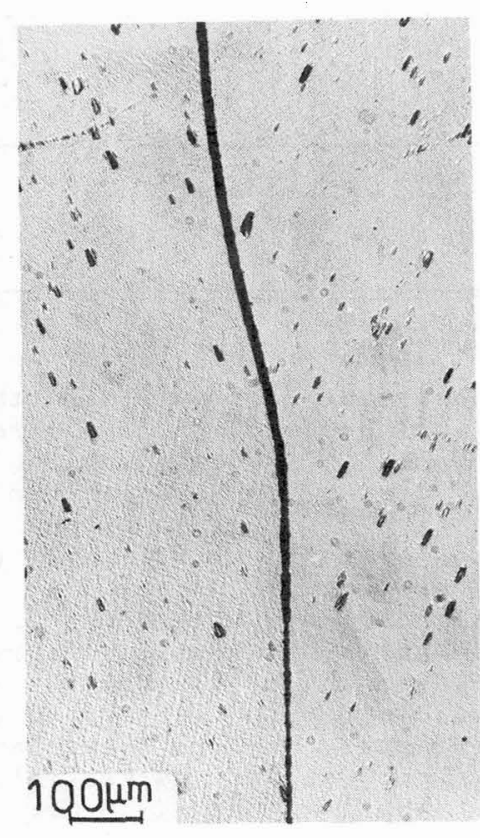

b

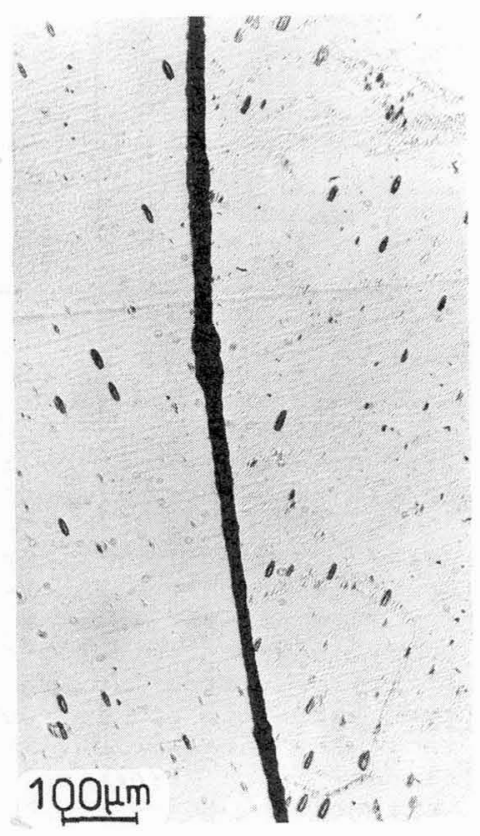

c

Fig 3 : Chemical etchings, observed perpendicularly to the growth direction : the groove is more or less deep according to the location in the bicrystal:

a) Part IA (symmetrical GB)

b) Part IB (asymmetrical GB)

c) Parts IIIA and/or B. 
The results of deviation from coincidence $\Sigma 11$, indices and (d/a)m of each GB plane before desulfidation and after desulfidation, are listed in Table II, and leads to the following remarks:

TABLE II : Influence of sulfur segregation on the deviation to 511 coincidence and on the $G B$ plane, before and after desulfidation.

\begin{tabular}{|c|c|c|c|}
\hline $\begin{array}{c}\text { GRAIN } \\
\text { BOUNDARY }\end{array}$ & $\begin{array}{l}\text { DEVIATION FROM } \\
\begin{array}{ll}\Sigma 11 & (\Delta \theta \text { deg }\end{array}\end{array}$ & $\begin{array}{l}\text { GRAIN BOU } \\
\text { INDICES }\end{array}$ & $\begin{array}{c}\text { DARY PLANE } \\
\left(\frac{d_{(h k L)}}{\partial}\right)_{m}\end{array}$ \\
\hline \multirow[b]{2}{*}{$I-A$} & $\begin{array}{l}\text { Before After } \\
\text { desulf. desulf. }\end{array}$ & $\begin{array}{l}\text { Before, After } \\
\text { desulf., desulf. }\end{array}$ & $\begin{array}{l}\text { Before | After } \\
\text { desul f. | desulf. }\end{array}$ \\
\hline & $\begin{array}{cl}0.50 & 10.50 \\
1 & 1 \\
\end{array}$ & $\begin{array}{ll}(\overline{1} 13)_{1} & (\overline{1} 13)_{1} \\
(1 \overline{1} 3)_{2} & (1 \overline{1} 3)_{2} \\
\end{array}$ & $0.300,0.300$ \\
\hline$I-B$ & $2.20: 1.90$ & $\begin{array}{l:l}(\overline{1} 12)_{1} & (\overline{1} 12)_{1} \\
(1 \overline{1} 7)_{2} & (1 \overline{1} 5)_{2}\end{array}$ & $0.170,0.200$ \\
\hline III_A & $\begin{array}{c}2.10,2.30 \\
1\end{array}$ & $\begin{array}{l:l}(\overline{2} 25)_{1} & (\overline{1} 3)_{1} \\
(1 \overline{1} 4)_{2} & (1 \overline{1} 4)_{2}\end{array}$ & $0.100,0.210$ \\
\hline III_B & $2.201-$ & $\begin{array}{l:}(\overline{1} 16)_{1} \\
(1 \overline{1} 2)_{2} \\
\end{array}$ & 0.145 \\
\hline
\end{tabular}

Before desulfidation: the symmetrical part of the GB IA with (311) plane is very close to the theoretical description $\left(0.5^{\circ}\right.$ from $\left.\Sigma 11\right)$. Others asymetrical GBs are deviated of $\sim 2^{\circ}$ from $\Sigma 11$, independently of the segregation level. The $(d / a) m$ values for these last GBs are much lower than the IA (d/a)m value.

After desulfidation: For the symmetrical $\Sigma 11$ (311) (part IA), no changes in the cristallographic parameters are noticed.

For the others GBs, no significant variations in the $\Delta \theta$ deviation from $\Sigma 11$ occur. However, changes in their GB planes are observed: the plane orientations after desulfidation are closer to (311) than the initial ones. In particular, the variation of $(d / a) m$ values for the segregated GBs are the largest ones and increase until 0.200 . The figure 4 plots interplanar distances of the four GB planes as a function of the sulfur concentration in the interface. It is worthnoting to remark that the limit of 0.150 for the $(\mathrm{d} / \mathrm{a}) \mathrm{m}$ value above which the segregation becomes unlikely in polycrystals [5] is still observed in case of bicrystal.

The GB plane varies with the segregation level. On the contrary, it seems that the sulfur content has no influence on the misorientation. Nevertheless, in the case of IB and IIIA GBs, it appears that the additional deviation axis Rd tends to be parallel to the [110] rotation axis; the angle value between $\mathrm{Rd}$ and $[110]$ is $\sim 16^{\circ}$ before desulfidation and $\sim 8^{\circ}$ after desulfidation: the [110] axis being contained in the GB plane, this observation implies a more pronounced tilt character of the departure from coincidence after desulfidation. 

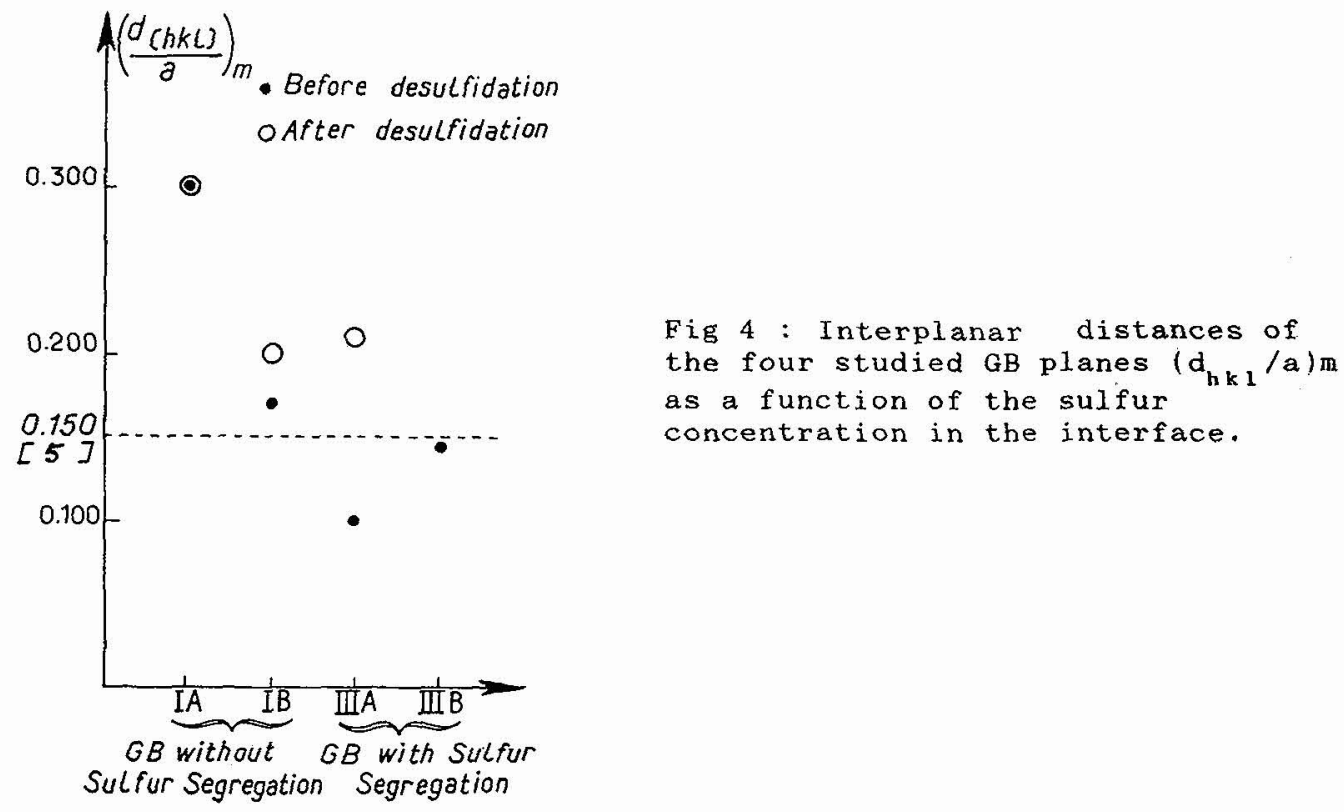

concentration in the interface.

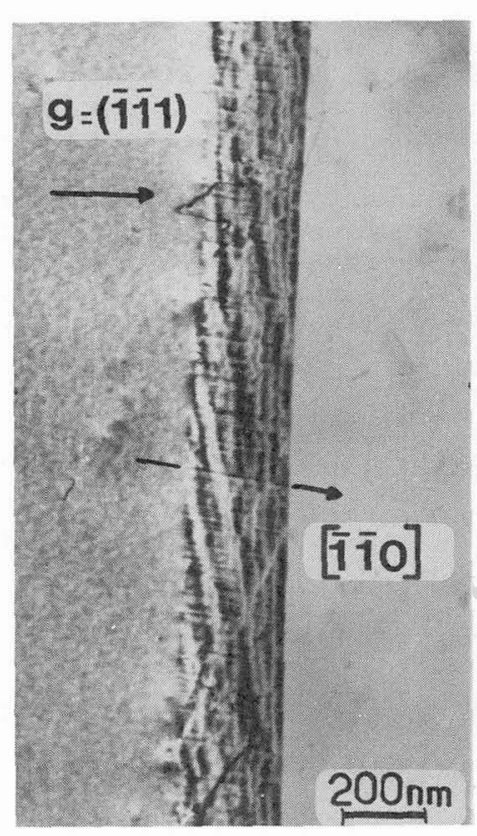

a

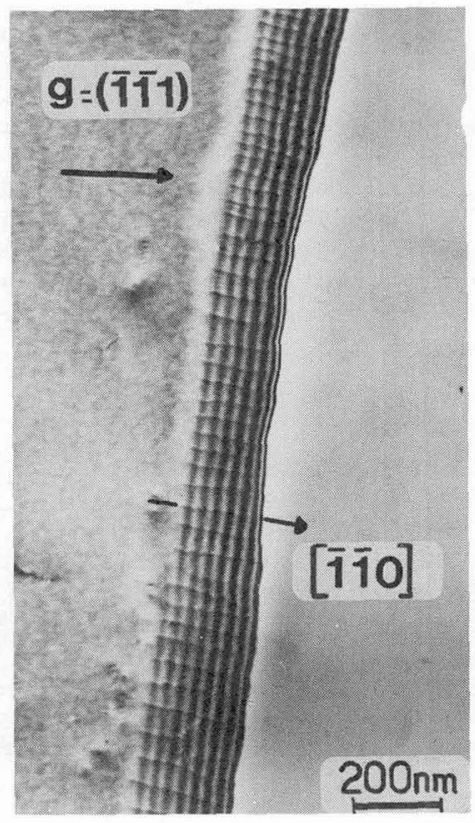

b

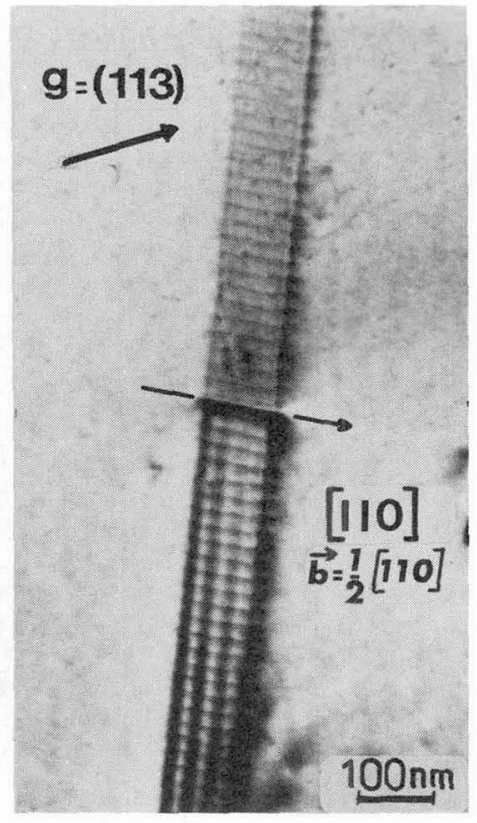

C

Fig 5 : TEM micrographs, bright field images :

a) part IA before desulfidation

b) part IB after desulfidation

c) part IIIA after desulfidation; note the fine intrinsic network of dislocations. 


\title{
INTERGRANULAR DISLOCATIONS
}

\begin{abstract}
Before desulfidation, the high number of trapped dislocations made not possible a detailed analysis of GB defects in parts I and III of the bicrystal ( fig $5 a$ ).
\end{abstract}

After desulfidation, as previously shown in polycrystals [6], the dislocations density strongly decreased whatever the location of the $G B$ in the bicrystal, thus independently of the initial sulfur content (fig $5 \mathrm{~b}$ and $\mathrm{c}$ ). All the GB contain a pseudo periodic network and a fine intrinsic network of dislocations lying both parallel to the [110] rotation axis. A few dislocations with a lattice Burgers vector $\vec{b}=1 / 2$ [110] that most prabably result from handling the thin foil, are also observed (fig $5 \mathrm{c}$ ).

The Burgers vector of the fine spaced dislocations could not be determined. It may correspond to a basal vector of the DSC lattice

$-\vec{b}=a / 22[\overrightarrow{3} 32]$ or $\vec{b}=a / 22$ [2 $\overrightarrow{2} 6]-$, both consistent with the measured periodicity and the tilt character of the deviation from coincidence. The large number of images analysed for the widely spaced dislocations permits to locate their Burgers vector within $25^{\circ}$ around the [110] axis, implying a marked twist character of the dislocations. This result allows possible Burgers vectors, either the lattice vector - 1/2 [110] - or any combination of this vector with the finely spaced dislocations vector i.e. $1 / 22[13,9,6]$ or $1 / 22[14,8,2]$. work is in progress to improve the determination of the Burgers vectors of these dislocations.

\section{CONCLUSION}

The experimental study of the interaction between intergranular segregation level and GB structure (deviation from coincidence, GB plane and dislocations) emphasizes the predominant role of the GB plane :

- the sulfur segregation concentration varies along a same $\Sigma 11 \mathrm{~GB}$;

- as"expected, the part of the GB with a symmetrical (311) plane, very close to equilibrium, does not contain any segregation and is very stable after the desulfidation treatment;

- on the contrary, all the segregated GBs present the same deviation from coincidence $\left(\Delta \theta=2^{\circ}\right)$; on the other hand, the GB plane varies with sulfur content: the lower $(d / a) m$ value, the higher the segregation level;

- when the sulfur is remoted from these GBs, the deviation from $\Sigma 11$ is not changed but the GB planes tend to be nearer (311) and associated (d/a)m values increase up to 0.200 .

\section{REFERENCES}

1 - A. SUTTON, R.w. BALLUFFI, Acta Metal1, 35, 2177, (1987).

2. - D. WOLF, Journal de Physique $n^{\circ} 4$, Colloque $C 4,197,(1985)$.

3 - D. WOLF, Acta Metall. 37,1983, (1989).

4 - V. PAIDAR, Phys, Stat. Sol. (a), 92, 1i5, (1985).

5 - D. BOUCHET, L. PRIESTER Scripta Met. 21, 475, (1987).

6 - D. BOUCHET, B. AUFRAY, L. PRIESTER, Journal de Physique, Colloque C5, $417,(1988)$.

7 - A. LARERE, M. GUILlOPE, K.I. MASUdA-JiNDO, Journal de Physique, Colloque C5, $t \quad 49,447,(1988)$.

8 - K. MARUKAWA, Y. MATSUBARA, Trans J.I.M. 20, 724, (1979). 